\title{
BMJ Open Cancer caregivers' experiences of prognosis in Australia: a qualitative interview study
}

\author{
Sophie Lewis (D) , ${ }^{1}$ Alex Broom (D) , ${ }^{2}$ Katherine Kenny (D) , ${ }^{2}$ Emma Kirby (i) ${ }^{1}$
}

\begin{abstract}
To cite: Lewis S, Broom A, Kenny K, et al. Cancer caregivers' experiences of prognosis in Australia: a qualitative interview study. BMJ Open 2020;10:e032361. doi:10.1136/ bmjopen-2019-032361
\end{abstract}

- Prepublication history and additional material for this paper are available online. To view these files, please visit the journal online (http://dx.doi org/10.1136/bmjopen-2019032361).

Received 20 June 2019 Revised 21 November 2019 Accepted 17 December 2019

Check for updates

(c) Author(s) (or their employer(s)) 2020. Re-use permitted under CC BY-NC. No commercial re-use. See rights and permissions. Published by BMJ.

${ }^{1}$ Centre for Social Research in Health, The University of New South Wales, Sydney, New South Wales, Australia

${ }^{2}$ School of Social and Political Sciences, The University of Sydney, Sydney, New South Wales, Australia

Correspondence to

Dr Sophie Lewis;

sophie.lewis@unsw.edu.au

\section{ABSTRACT}

Objectives Forecasting survival in cancer is a particularly challenging facet of oncological work and can involve complex interactions with patients and their families. While there is considerable research on patient experiences of being provided with, or becoming aware of, their prognosis, there has been much less emphasis placed on the experiences of caregivers. The aim of this paper was to examine caregivers' experiences of prognosis.

Design This study used semistructured interviews; transcripts were analysed thematically using the framework approach. These data are part of a larger research project focused on experiences of cancer survivorship.

Setting Recruitment was from two metropolitan hospitals in Queensland, Australia.

Participants 50 caregivers of patients living with cancer and receiving treatment at two metropolitan hospitals (32\% male, 68\% female) participated in this study.

Results Four main themes were identified: (1) caregivers' uncertainty around the meaning and implications of prognosis, (2) caregivers' sense of exclusion in prognostic conversations, (3) the practice of situating prognosis within a context of hope and (4) the precarious balance between realism, optimism and strategic 'ignorance'.

Conclusions Caregivers are in many respects the unseen third party of prognostic communication. Developing a better understanding of caregivers' perceptions of prognosis, including how this may be challenged, accepted or otherwise, is important in engaging caregivers in the process of communicating prognostic information. Facilitating greater participation by caregivers in prognostic conversations could potentially address evident complexities and even improve the experiences of all stakeholders in cancer care settings.

\section{INTRODUCTION}

Delivering news about the likely course of illness and mortality risk is a central part of oncology practice and has inspired a large body of clinical literature on communicating (often difficult) information. ${ }^{12}$ Much of this research focuses on how health professionals should communicate about a cancer diagnosis, ${ }^{3}{ }^{4}$ while somewhat less attention has been paid to specific interactions around prognosis or clinical forecasting. ${ }^{56}$ Furthermore, most studies exploring prognostic

\section{Strengths and limitations of this study}

This qualitative study uses semistructured interviews to provide critical insights into the complexities that caregivers experience in contexts where there is considerable uncertainty about the patient's future.

- Our sample included participants caring for patients with a diverse range of illness experiences, cancer types and different cancer trajectories.

- Recruitment was from two metropolitan hospitals in one city, limiting the transferability to other settings.

- The cross-sectional study design limits what can be claimed to prevail across time in changing oncology treatment contexts.

- The findings were inductively derived from an analysis of participants' accounts.

exchanges in therapeutic settings examine patients' experiences ${ }^{7-11}$ versus those of caregivers. This is despite the very different interpersonal and emotional impacts that diagnosis (eg, of cancer) and prognosis (eg, of a very short time to live) each have across stakeholders.

While prognosis broadly refers to 'the likely outcome or course of a disease; the chance of recovery or recurrence, ${ }^{12}$ in practice, diagnosis and prognosis are often bundled together in both therapeutic encounters and in scholarly research. Yet, prognostic conversations entail a much greater degree of precarity for patients and caregivers, ${ }^{13}$ as conversations turn to very concrete ideas or statements such as 'years or months left', 'the likelihood you will beat this' or 'your chances of cure', versus rather more abstract notions of cancer of a particular region of the body. As such, prognostic conversations have a very different feel within therapeutic encounters as compared with conversations about a cancer diagnosis. Prognosis is, in turn, often, although not always, a precarious and even speculative practice for oncologists seeking to guide individual patients (and their caregivers) based on historical population data 
and/or clinical experience. ${ }^{1516}$ Prognosis can therefore be an intense and difficult site of interaction for patients, their caregivers and oncologists.

Although there has been research exploring caregivers' perspectives about how patients responded to prognosis, little emphasis has been placed on caregivers' own experiences and perspectives. ${ }^{17-19}$ This has created a tendency to oversimplify how prognosis is received (ie, only in relation to the patient vis-à-vis carers and/or family). Such emphases filter down to policy and sometimes clinical practice. Specifically, a singular emphasis on patients, and considering caregivers as virtual (and concurring) extensions of patients in terms of how prognosis is received. This is manifest in the (often implicit) logic of dealing with caregivers in conjunction with patients. ${ }^{20}$ While this protects patient autonomy, it also presupposes a degree of concordance between patients and their caregivers around what (and how much) they want to know about prognosis, as well as how they will react to this information.

Social research on prognosis has revealed some of the interpersonal aspects of clinical encounters including the use of evasion, euphemism and anecdotes of outliers in order to maintain hope, preserve patient-clinician relationships and foreground a 'silver lining' within bad news. ${ }^{22-24}$ Of the research that has been completed on caregivers' experiences of prognosis in oncology environments, the majority has been conducted in palliative care settings, ${ }^{25} 26$ with a focus on concerns specific to the end of life, and the negative impacts on caregivers' quality of life. ${ }^{27}$ We still have very little knowledge about how caregivers experience prognostic encounters around cancer, including how they navigate their own need for knowledge and understanding (eg, certainty and realism), alongside the needs of the person for whom they are caring (eg, hope and optimism). It is this gap in understanding that we seek to fill here. The aim of this paper was thus to examine informal caregivers' perspectives and experiences of cancer prognosis.

\section{METHODS}

Taking an interpretive approach to research design, data collection and analysis, this paper draws on data from 50 qualitative semistructured interviews which sought to generate in-depth examination of the experiences of individuals caring for patients with cancer and receiving treatment at one of two metropolitan hospitals in Australia. These data are part of a larger research project examining patients', informal caregivers' and health professionals' experiences of cancer survivorship and supportive care. ${ }^{28} 29$

\section{Sampling and recruitment}

Carers were recruited via convenience sampling through participating patients who were purposively sampled to ensure diversity of experiences of living with cancer and different cancer types. Caregivers were recruited via patients who had consented to having members of the research team contact their nominated caregiver. Working with clinicians in a medical oncology clinic, initially patients were approached by their treating clinician or a researcher, who explained the study aims and methods. Interested patients were asked if they would like to nominate a partner, family member or friend who played a role in their care to be contacted for an interview. The researchers then contacted nominated caregivers. Interested caregivers were provided with an information sheet outlining the aims of the study, and were contacted to schedule a time for an interview. The inclusion criteria for caregivers to participate in the study were that they had been nominated by a patient participant, were aged 18 years or older and were proficient in English. Recruitment of participants continued until consensus among research team members that saturation had been reached.

\section{Data collection}

One-on-one, semistructured interviews were conducted between August 2015 and January 2017 with caregivers, after they provided informed written consent. Interviews ranged in duration from 25 to 70 min (mean 47, median 48.5), and were conducted by four research team members with qualitative interviewing and social science expertise, in a location chosen by the participant such as a hospital meeting room or the caregiver's home. Using an interview guide (online supplementary file 1), the interviews explored the following topic areas: everyday practices and experiences of caring for a person living with cancer, consequences of cancer for relationships and the interactional dynamics between caregivers and patients, caregiver interactions within the healthcare system and experiences of cancer care within and outside of the hospital setting. The interview guide was discussed and restructured iteratively based on analysis of earlier interviews. Interviews did not focus specifically on prognosis, but this was a key issue raised by participants throughout. The findings are derived inductively from analysis of participants' interviews. Interviews were digitally recorded and transcribed verbatim. Transcripts were deidentified, and each participant was assigned a code.

\section{Data analysis}

Our approach to analysis was thematic and inductive, using a framework approach. ${ }^{30}$ This approach involved the following steps: first, after checking for accuracy, transcripts were repeatedly read, and notes were made about emerging ideas and themes within each transcript. Data were organised around the key themes and ideas (identification of the framework), and through this process, broader themes were developed to encapsulate the experiences of participants and build a picture of the data as a whole. Transcripts were coded independently by three members of the research team. Codes reflected participants' views about cancer, cancer trajectories and prognosis, and how this intersected with their experiences of caring for a patient living with cancer, perceptions of their 
roles and responsibilities, and how they navigated their relationships and interactions with patients and health professionals. Codes were discussed among the authors, who looked for emergent patterns and anomalies across interview transcripts and to confirm consistency of interpretation of the data. QSR NVivo V.12 was used to manage and organise the data. Analytical rigour was enhanced by searching for any contradicting cases in developing the themes. ${ }^{31}$ An audit trail was provided by keeping a detailed record of sampling, recruitment and coding processes, audio recordings, transcripts and detailed field notes. The SRQR qualitative research reporting checklist was used to ensure comprehensive reporting. ${ }^{32}$

\section{RESULTS}

A total of 50 informal caregivers participated in the study, 34 female and 16 male. Participants' relationship to the person they were caring for were their partner $(n=32)$, child $(n=11)$, parent $(n=3)$, friend $(n=2)$, sister $(n=1)$ or son-in-law $(\mathrm{n}=1)$. Table 1 provides further details about caregivers' characteristics. Table 1 also includes details of the stage at diagnosis, treatment intent at the time of interview and cancer type for the patient participants were caring for, offering further context around prognosis. (We are careful here to avoid making associations between participants' understandings and lived experiences of prognosis, and clinical information about cancer stage at diagnosis, and treatment intent, as these may not align.)

In our study, we sought to better understand caregivers' experiences around prognosis. Discussion about prognosis, including how much (or little) prognostic information is shared between health professionals, patients and caregivers, is a complex terrain for all to navigate. This is especially the case for caregivers, who must also navigate the interpersonal dynamics of uncertainty and dependency with their care recipient. We identified four overarching themes: (1) caregivers' uncertainty around the meaning and implications of prognosis; (2) caregivers' sense of exclusion in prognostic conversations; (3) situating prognosis within a context of hope; and (4) the precarious balance between optimism, realism and strategic 'ignorance'.

\section{Caregivers' uncertainty around the meaning (and implications) of prognosis}

One prominent theme in our analysis was a tension between caregiver desires, needs and emotions around prognosis and those (they perceived) of the patient. Although there were caregivers in our cohort who said they were 'on the same page' about prognosis, and the value of prognostic knowledge, as the patient, the majority of participants described having divergent perspectives on the value of hearing about prognosis. Most caregivers expressed their 'need for more information' about the prognosis than the person they were caring for. Caregivers described wanting to be better informed about prognosis,

\begin{tabular}{lc} 
Table 1 Participant characteristics & \\
\hline Participant characteristic & $\mathbf{n}=\mathbf{5 0}(\%)$ \\
\hline Caregiver sex & \\
Male & $16(32)$ \\
Female & $34(68)$ \\
Caregiver relationship to patient & \\
Partner & $32(64)$ \\
Child & $11(22)$ \\
Parent & $3(6)$ \\
Sibling & $1(2)$ \\
Son/Daughter-in-law & $1(2)$ \\
Friend & $2(4)$ \\
Patient stage at diagnosis & \\
Early stage & $8(16)$ \\
Locally advanced & $3(6)$ \\
Advanced/Metastatic & $39(78)$ \\
Patient treatment intent at time of interview (according to \\
medical records) & \\
Palliative intent & $33(66)$ \\
Curative intent & $7(14)$ \\
Observation & $5(10)$ \\
Follow-up post-treatment & $4(8)$ \\
Follow-up (declined treatment) & $1(2)$ \\
Patient cancer type & $17(34)$ \\
Lung & $11(22)$ \\
Neuroendocrine (NET) & $8(16)$ \\
Colorectal & $7(14)$ \\
Brain & $2(4)$ \\
Breast & $1(2)$ \\
Head and neck & $1(2)$ \\
Melanoma & $1(2)$ \\
Sarcoma & $1(2)$ \\
Mesothelioma & $1(2)$ \\
\hline Thymoma & \\
\hline
\end{tabular}

which was described by some as wanting to 'know the truth'. These caregivers desired prognostic information in order to gain greater certainty, to moderate their own emotions in order to care effectively and to be better able to plan for the future. Such planning included emotional preparation on the part of the caregiver, but also supporting the patient (and other family members/ loved ones) to prepare for the 'next phase' (eg, treatment, for decline, for the end of life and so on). As the quotes in table 2 illustrate, caregivers expressed a need to know what to expect, including 'hope for the best, plan for the worst' scenarios. Such contingency planning was associated with ideas of being a good caregiver, 'doing everything you can' and making good decisions about care. This included avoiding complacency, being 
Table 2 Indicative quotes: uncertainty around the meaning of prognosis

\begin{tabular}{ll}
\hline Participant & Indicative quote \\
\hline \#19, wife of patient & $\begin{array}{l}\text { It's hard when we go to the oncologist because he [my husband] doesn't want to know anything and } \\
\text { so I can't ask in front of him or anything like that. Like, my gosh, I think as soon as he gets told his } \\
\text { scan is still the same he's up and out the bloody door. Dr [Name] has to pull him back. So it's really } \\
\text { hard. I talk to my GP. He's been very good. He's told me a few things. }\end{array}$ \\
\#44, wife of patient & $\begin{array}{l}\text { I suspect that he [my husband] would say he would have preferred not knowing. From a mum } \\
\text { perspective and a wife perspective, I still think if I was put back in this situation I would still ask [for } \\
\text { the prognosis]. I don't think he would though. [...] I have thrown a positive spin, at least knowing the } \\
\text { timeframe or a potential timeframe has given us an opportunity to do things that we would never }\end{array}$ \\
have done.
\end{tabular}

vigilant, providing support and advocating for 'the best' treatment. The tensions between patients' and caregivers' preferences for prognostic information, described by participants, add a layer of complexity to understanding clinical encounters in oncology and highlight some of the challenges faced by health professionals when determining how (and how much) to convey to patients and caregivers about prognosis.

\section{Caregiver exclusion and the 'back stage' search for more information}

Caregivers' accounts of prognosis also revealed experiences of (self-)exclusion or silences within clinical consultations (see table 3). Caregivers' accounts revealed instances where they felt shut-out of clinical appointments (by patients and/or health professionals), or where, while

Table 3 Indicative quotes: exclusion and back stage search for information

\section{Participant Indicative quote}

\#15, daughter of patient My mum's very stoic. She doesn't really express. If it's bad news she'll hold it close to her chest. Also, you're just sort of, "Well what exactly did they say?" because sometimes I don't think I get the truth. [...] She doesn't want to burden us. She doesn't want us to worry. We worry when we don't know because we're worried about what the result is.

\#40, sister of patient I just basically rely on the information that he tells me. Sometimes I don't think he tells me everything. [...] There's been some conversations when he's mentioned stuff and I'm like, "Yeah, you're not telling me everything." But, at the same time, I think he tells me what he thinks I need to know.

\#47, female partner of I research a lot of things. I always like to know. Sometimes [partner] says, "Don't look at it," and I say, patient "But I need to know. If you don't want to look at it that's fine, but I need to know what we are dealing with, how. That makes me feel better."

\#6, daughter of patient I did look up what sort of life expectancy there would be with what mum's got and I haven't shared that with her. But that was just for me to feel like I could judge how much time we've got.

\#44, wife of patient There was definitely questions. I wanted more and I didn't get it, and I think that's why I went off to try and find the answers myself and I didn't like what I was hearing. But then, I was trying to read through all the medical mumbo-jumbo. So then I was thinking, "Well maybe I'm reading this wrong. [...] So I would have liked more. Even though it was going to be bad, it would have saved me a lot of time and heartache [compared to] going to find the information myself. I would have really just loved an opportunity of somebody sitting down and really laying it out on the table. But it was never laid out on the table. So we always walked away questioning, "Well maybe it's not so bad," and then you would go and read something, "Well maybe it really is bad." So you really never knew exactly where we stood. 
present in the consultation, they felt unable to participate, or not worthy of participation, in conversations. In these circumstances, caregivers recounted hesitations about their role and rights within the consultation, with a tendency to (reluctantly) sideline themselves within conversations about prognosis. This created situations where carers were reliant on patients for clinical information. However, in circumstances where patients did not wish to know the prognosis, or when caregivers perceived that patients were keeping information from them, caregivers were uneasy or reluctant to push patients to disclose information that they chose not to freely share. There was a perception that if patients chose not to share, caregivers should not ask. While participants recognised the validity and importance of situating care and disclosure around patient need, they also described these times of exclusion and silences in and beyond therapeutic encounters as important sources of distress or apprehension. Participants also recognised patient withholding of information was invariably intended to protect loved ones and not burden them with bad news. Yet, such practices often paradoxically induced helplessness and resignation. What resulted was a virtual paralysis between the importance of respecting the wishes of the patient and appeasing their own right to know.
This dynamic was reported to invariably result in a range of covert information-seeking strategies. Many caregivers actively sought out additional information from alternative sources, mainly via internet-based research or from their own health professional (eg, their general practitioner). The importance of prioritising the patients' preferences and needs above their own was stressed, for example, by using variations of sentiments such as: 'it's not about me'. Although carers reported outwardly supporting patients' wishes, beyond these interactions they sought out further information about prognosis online. Yet this practice could be problematic, with participants describing being exposed to distressing, anxietyprovoking and even inaccurate information that could not be 'unseen' or 'unlearned'. This reveals the potential unintended consequences of caregivers' marginalisation from clinical conversations about prognosis.

\section{Situating prognosis within a context of hope}

Participants provided detailed accounts of how they experienced discussions with health professionals about the cancer prognosis, and the various ways in which they interpreted and responded to these conversations. As the indicative quotes in table 4 illustrate, caregivers recounted how prognosis was conveyed, describing how 'bad news'

Table 4 Indicative quotes: situating prognosis within a context of hope

Participant Indicative quote

\#29, husband of patient Then she got diagnosed with cancer in the breast, in the liver. That was a bit of a problem. So from there I said to him [the doctor], "What's the prognosis?" and he said, "Well, not really good. But don't take it as that. You keep pushing forward." This is what, basically, we've done.

\#3, daughter of patient The oncologist was like, "You know what, that timeframe, ignore it. We will do what we can, and we might be able to get years for you." That went from going, "Oh my god, we've only got like six to 12 months," to, "Okay, she's got terminal cancer. She's still got it, never going to be cured. But, we have time."

\#28, wife of patient From the time he was told he's got it he's never been told any bad news since. It's always been positive. So he's got a positive outlook on it.

\#11, wife of patient I think when we got the liver diagnosis [...] that was quite confronting for me, but then when we got into the swing of chemo, $\mathrm{Dr}$ [Name] just gave us the impression of this is a maintenance thing. We'll keep it at bay like this.

\#4, daughter of patient I did ask once, I did ask Dr [Name] if the prognosis had changed at all like, "Is it any better? Is it any worse?" and she said, "The prognosis is not going to change. Terminal is terminal. It's not going to change.

\#10, husband of patient [Doctor's name] said, fairly bluntly, "The fiveyear survival rate is less than $20 \%$." It's not easy to say this, but I think whether he meant to or not, the message that he was putting across, the nonverbal message was "Forget it. It's all over," which was pretty difficult. But then I was able to reassure [wife's name] that - and it's true - the stats are historic [...] the prognosis keeps improving.

\#44, wife of patient Looking back we'd not want to know, maybe. Because now we've got these time markers our whole lives are revolved around those.

\#3, daughter of patient When I was looking at the different stages of the secondaries in the lung and relating it to what mum's got it's like, "Okay, I think she's at that stage. I'm really not happy knowing that."

\#1, female partner of I think he's protective in that when I'd come up to meet him I wanted to meet the doctor but he'd patient go, "The doctor hasn't come today." I think he just wanted me not to be there. I think he was protecting. He wasn't asking questions. He didn't give me much detail... [My] mum said, "Why don't you just speak to the nurse when you come in and try and find out what's really going on?" That was a bit tough. 
was often front-loaded in interactions, before health professionals shifted the conversation towards more positive aspects of the situation such as options for treatment (regardless of curative or palliative intent). This situated prognosis within a context of hope and optimism. This was viewed by many caregivers as helpful in coping with and moving beyond what was often 'confronting' and 'distressing' news. This was particularly evident in cases of terminal prognosis where knowledge that there 'was time', 'hope' or a 'positive outlook' provided some comfort to caregivers. Yet, caregivers reported positioning themselves as bystanders or spectators to doctor-patient interactions. Although caregivers' accounts suggested that they were unwilling to involve themselves in discussions about prognosis, these relational silences resulted in unresolved questions and uncertainties around whether prognosis had changed (or improved), especially as the time since initial diagnosis increased. Caregivers' accounts also revealed that within this cohort there was a range of preferences for information about prognosis, ranging from caregivers who never wanted to talk about the prognosis to those who wished to have more regular or ongoing conversations about the patient's condition and outlook. The variety of experiences of caregivers in our cohort presents a challenge for health professionals when communicating prognostic information given that caregivers' preferences are diverse.

\section{"I'm more realistic": balancing optimism, realism and strategic 'ignorance'}

Finally, caregivers' accounts suggested that prognosis grounds a range of (sometimes competing) objectives for patients and caregivers. Caregivers felt that maintaining hope, quality and duration of life were objectives prioritised by patients, which they shared. Yet, caregivers' priorities also centred on preparing and planning for the future. As a result, caregivers experienced a range of tensions around information about prognosis. Our analysis revealed the ways by which carers positioned themselves as needing to be more realistic and practical than patients, who could choose to remain 'blissfully ignorant'. Reconciling these often competing objectives was a key source of tension for caregivers. Caregivers emphasised the need to manage their own expectations and desires alongside the patients' needs. But finding a balance between realism and hopefulness was complicated, challenging and often fraught. While caregivers recognised the potential therapeutic role of hope and optimism, they also described how being unrealistic could sometimes be detrimental. It is important to note that for most caregivers, realism and optimism were not positioned as mutually exclusive. Thus, participants described trying to maintain hope for the future, without 'being unrealistic' or 'in denial' within a context of ever-changing symptoms and expectations for care. As the indicative quotes in table 5 show, carers want to retain hope but feel the need to plan and prepare for the future. This was especially prominent in circumstances where the cancer was non-curative and caregivers 'needed to be prepared' for when the patient's condition deteriorated and they were required to make decisions about end-of-life care (and beyond). This points to the different roles that caregivers may play (eg, of care provider and of loved one), and the complex range of emotions that come with the competing obligations of these different roles; for example, the

\begin{tabular}{|c|c|}
\hline Participant & Indicative quote \\
\hline$\# 38$, wife of patient & $\begin{array}{l}\text { I am hopeful... I'm realistic in the fact that he probably won't be around. But l'm also hopeful that we've } \\
\text { probably got more time than it sometimes sounds. <crying }>[. . .][\mathrm{He}] \text { tries to be really positive with } \\
\text { them (the kids), but I try to be more realistic as well and tell them that he had cancer, they did know } \\
\text { about cancer, and that we just didn't know what our future was. Hopefully he would get well, but there's } \\
\text { a possibility that he might not, and he might not be around as long as we'd thought. }\end{array}$ \\
\hline$\# 43$, wife of patient & $\begin{array}{l}\text { I just don't want to be completely devastated. I've got an acceptance, but l've got a lot of hope and } \\
\text { that's what I said to the doctor yesterday, "We're fairly practical, we're fairly logical and realistic, but } \\
\text { we're hopeful." }\end{array}$ \\
\hline$\# 19$, wife of patient & $\begin{array}{l}\text { I think we should have conversations like that [about cancer progression] more often. I'm more realistic } \\
\text { and it would help me. I like to be planned as much as I can. (I: Have you told him that?) No. No, I } \\
\text { haven't. Because I don't want to upset him. [...] I think he's got blind hope. I feel I've got to be more } \\
\text { practical, but I also have to be here for (the) children. }\end{array}$ \\
\hline $\begin{array}{l}\text { \#29, husband of } \\
\text { patient }\end{array}$ & We live in hope that it will go away. I really think, possibly, it's a bit of a pipedream. \\
\hline $\begin{array}{l}\text { \#35, husband of } \\
\text { patient }\end{array}$ & $\begin{array}{l}\text { Also, we're quite well aware that sometime down the track the days are going to get really bad, maybe. } \\
\text { Maybe they won't. Maybe we'll be lucky. Maybe it will just stay like this in the indefinite future. }\end{array}$ \\
\hline $\begin{array}{l}\text { \#21, husband of } \\
\text { patient }\end{array}$ & $\begin{array}{l}\text { You hope for a cure or at least to be stabilised to return to some level of health, healthy lifestyle, things } \\
\text { like that. I suppose it's a case of looking at it from two angles. One is, get your house in order, but then, } \\
\text { I guess the way l've gone, is just make sure you enjoy every day because you never know what your } \\
\text { fate could be. They might be sick, but I could walk out there and get hit by a truck or something can } \\
\text { happen, and you see that. }\end{array}$ \\
\hline
\end{tabular}


guilt of seeming to have 'given up hope' or the stress of 'putting your life on hold'.

\section{DISCUSSION AND IMPLICATIONS FOR PRACTICE}

Prognosis communication is an interpersonal, collective process, with consequences felt much more broadly than within the experiences of patients alone (or clinicians who have to manage the delivery of such information). Caregivers are in many respects often the unseen third party of prognostic communication. They are, as they selfdescribe here, variably and problematically: positioned as bystander yet are key actors in the scene; expected to balance within prognosis realism and optimism; and finally, they play a central role in the emotional work of managing the benefits and undermining effects of prediction in cancer care. Yet, most work on the dynamics of delivering and receiving prognoses has tended to conceal caregivers within the broader lay reception of forecasting in oncology. Here, we make a critical contribution to research, offering new insight into the often sidelined, yet still vital experiences of caregivers, revealing their experiences of cancer forecasting in contexts where there is considerable uncertainty about the patient's future. ${ }^{171833}$

Caregivers may experience tensions around their preferences for knowledge on clinical forecasting and their desire to protect patients from potentially 'bad news', 171934 and this can have implications for cancer caring. ${ }^{35}$ Although carers' narratives suggest divergences in approaches to prognosis between carers and the patients they care for, they also reveal that, at least from their perspectives, clinical encounters are often not set up to ameliorate this due to the primacy of patient autonomy and privacy. This offers the potential for countervailing forces, including such encounters being relational but also individualised. As a result, caregivers may feel that there are limited opportunities to participate in discussions, even though these discussions greatly affect them, as well as the patients themselves. ${ }^{36}$

One step towards better accommodating both patient and caregiver needs could be for health professionals working in oncology to be open in their interactions with patients and caregivers about the potential for patients and caregivers to have diverse, and possibly divergent, preferences for prognostic information. Taking a familycentred approach-which recognises the patient as one node within a broader landscape of significance-to prognosis could mean thinking of ways to create spaces and orchestrate opportunities for discussions with carers about what matters to them, and how their desires can be supported. ${ }^{37}$ This includes how caregivers could be better supported in situations where they feel like they become mere spectators, or are positioned at the periphery of interactions between patients and health professionals. This has important implications, especially within the context of the formal healthcare systems where caregivers may encounter barriers in their access to information due to concerns about patient privacy. ${ }^{37}$
Social science scholarship in the field has shown that clinicians may couch clinical forecasting within a rhetoric of optimism and ambiguity to foster positive therapeutic relationships. ${ }^{24} 3839$ Our findings reveal the varied and complex responses of carers to the presentation of prognosis in positive or ambiguous ways. ${ }^{40} 41$ Although "clinical bright-siding' can preserve hope and optimism, ${ }^{23}$ it may also, as our findings suggest, reinforce the silences or uncertainties around prognosis. ${ }^{42}$ This places additional expectations on carers surrounding how to balance (often competing) desires for optimism, realism, ignorance and knowledge, disrupting carers' imagined caring expectations and roles, and creating new forms of guilt and suffering. ${ }^{25} 43$

Finally, prognosis is not a single predictive moment, but an unfolding and negotiated process that caregivers are integral actors, but not always active participants, in, and which strongly shapes their lived experiences. ${ }^{39}$ Not only are there clear differences, from the perspective of caregivers themselves at least, between their personal preferences and wishes, and those of the people they are caring for, but caregivers' preferences are not fixed, and are in constant flux in relation to the changing expectations and experiences of themselves, and of patients. This raises questions about whether we might rethink approaches to prognosis-related discussions, and whether there might be more exploration of how health professionals could be guided by patients and carers about their wishes. It also raises the question of the extent to which finding the right way for health professionals to deliver prognoses ('good', 'bad' or otherwise) fits within a person-centred and indeed family-centred approach to cancer care. Rather than finding the best way to communicate this kind of information, which can place pressure on clinicians to 'get it right', it may be as important to appreciate that delivering prognoses may look different for carers in different circumstances. ${ }^{42}$

A key strength of our study is that it provides rich insights into how cancer forecasting is experienced by caregivers, whose perspectives have previously received limited research attention. Our sample included participants caring for patients with a range of illness experiences, cancer types and stages. Our study has several limitations. Most participants were female and/or partners of patients, and recruitment was from two metropolitan hospitals in one Australian city, limiting the transferability to other settings. The cross-sectional study design also limits what can be claimed to prevail across time in the context of ever-changing oncology treatments and agendas. The findings reported in this article were inductively derived from the analysis of participants' accounts; as such, the analysis is limited as participants were not explicitly questioned about prognosis. The participant accounts provided are also limited to perspectives of caregivers in circumstances where the patient was still engaged with healthcare or treatment for their cancer. Future research including the perspectives of caregivers of patients not currently engaged with healthcare and/or 
treatment, male caregivers and caregivers with different relationships with patients is needed. While the focus of this study was on caregivers' perspectives, future research exploring the experiences of, and interactions occurring between, patients, informal caregivers and health professionals is also required to more comprehensively capture the processes involved in prognostic conversations. Developing a better understanding of the perspectives and experiences of caregivers about prognosis is important in engaging caregivers in the process of communicating prognostic information. Facilitating greater participation by caregivers in prognostic conversations could potentially address evident complexities and even improve the experiences of all stakeholders in care settings.

Twitter Sophie Lewis @lewis_soph, Alex Broom @BroomAlex, Katherine Kenny @ kennykatherine and Emma Kirby @DrEmmaKirby

Acknowledgements We thank Associate Professor David Wyld and Associate Professor Zarnie Lwin for their contribution to study design and recruitment. We thank all the participants for sharing their experiences with us.

Contributors The project was designed by $\mathrm{AB}$ and EK. Data were collected by $A B, K K$ and EK, and analysed by SL, AB, KK and EK. All authors contributed to the drafting and revising of the manuscript and approved the final version.

Funding This work was supported by funding from an Australian Research Council Discovery Project (DP150100414) and Australian Research Council Fellowships (DE150100285 and DE170100440).

Competing interests None declared.

Patient and public involvement statement Patients and the public were not involved in the design of the study. The study is designed to explore and reveal patients' and informal caregivers' experiences of living with cancer. Reports and publications will be made available to participants on request.

Patient consent for publication Not required.

Ethics approval Ethics approval was gained through a large metropolitan hospital (approval number HREC/15/QRBW/65).

Provenance and peer review Not commissioned; externally peer reviewed.

Data availability statement Data are available on reasonable request.

Open access This is an open access article distributed in accordance with the Creative Commons Attribution Non Commercial (CC BY-NC 4.0) license, which permits others to distribute, remix, adapt, build upon this work non-commercially, and license their derivative works on different terms, provided the original work is properly cited, appropriate credit is given, any changes made indicated, and the use is non-commercial. See: http://creativecommons.org/licenses/by-nc/4.0/.

\section{ORCID iDs}

Sophie Lewis http://orcid.org/0000-0003-4639-217X

Alex Broom https://orcid.org/0000-0003-1258-1140

Katherine Kenny https://orcid.org/0000-0001-9088-5671

Emma Kirby http://orcid.org/0000-0001-9754-0342

\section{REFERENCES}

1 Bousquet G, Orri M, Winterman S, et al. Breaking bad news in oncology: a metasynthesis. JCO 2015;33:2437-43.

2 Fallowfield L, Jenkins V, sad C. Bad, and difficult news in medicine. Lancet 2004;363:312-9.

3 Fallowfield L, Jenkins V. Effective communication skills are the key to good cancer care. Eur J Cancer 1999;35:1592-7.

4 Girgis A, Sanson-Fisher RW. Breaking bad news. 1: current best advice for clinicians. Behav Med 1998;24:53-9.

5 Chou W-yingS, Hamel LM, Thai CL, et al. Discussing prognosis and treatment goals with patients with advanced cancer: A qualitative analysis of oncologists' language. Health Expectations 2017;20:1073-80.

6 Parker SM, Clayton JM, Hancock K, et al. A systematic review of prognostic/end-of-life communication with adults in the advanced stages of a life-limiting illness: patient/caregiver preferences for the content, style, and timing of information. J Pain Symptom Manage 2007;34:81-93.

7 Butow PN, Maclean M, Dunn SM, et al. The dynamics of change: cancer patients' preferences for information, involvement and support. Annals Oncol 1997;8:857-63.

8 Hagerty RG, Butow PN, Ellis PM, et al. Communicating prognosis in cancer care: a systematic review of the literature. Annals Oncol 2005;16:1005-53.

9 Hagerty RG, Butow PN, Ellis PM, et al. Communicating with realism and hope: incurable cancer patients' views on the disclosure of prognosis. JCO 2005;23:1278-88.

10 Thorne S, Hislop TG, Kuo M, et al. Hope and probability: patient perspectives of the meaning of numerical information in cancer communication. Qual Health Res 2006;16:318-36.

11 Thorne SE, Hislop TG, Armstrong E-A, et al. Cancer care communication: the power to harm and the power to heal? Patient Educ Couns 2008;71:34-40.

12 National Cancer Institute. Understanding cancer prognosis. 2018, 2019. Available: https://www.cancer.gov/about-cancer/diagnosisstaging/prognosis

13 Enzinger AC, Zhang B, Schrag D, et al. Outcomes of prognostic disclosure: associations with prognostic understanding, distress, and relationship with physician among patients with advanced cancer. $J$ Clin Oncol 2015;33:3809-16.

14 Kimbell B, Murray SA, Macpherson S, et al. Embracing inherent uncertainty in advanced illness: table 1. BMJ 2016;354:i3802.

15 Stone PC, Lund S. Predicting prognosis in patients with advanced cancer. Annals of Oncology 2007;18:971-6.

16 Temel JS, Shaw AT, Greer JA. Challenge of prognostic uncertainty in the modern era of cancer therapeutics. JCO 2016;34:3605-8.

17 Clayton JM, Butow PN, Tattersall MHN. The needs of terminally ill cancer patients versus those of caregivers for information regarding prognosis and end-of-life issues. Cancer 2005;103:1957-64.

18 Krawczyk M, Gallagher R. Communicating prognostic uncertainty in potential end-of-life contexts: experiences of family members. BMC Palliat Care 2016;15:59.

19 McCarthy B. Family members of patients with cancer: what they know, how they know and what they want to know. Eur J Oncol Nurs 2011;15:428-41.

20 Curtis JR, Engelberg R, Young JP, et al. An approach to understanding the interaction of hope and desire for explicit prognostic information among individuals with severe chronic obstructive pulmonary disease or advanced cancer. J Palliat Med 2008;11:610-20.

21 Kirk P, Kirk I, Kristjanson LJ. What do patients receiving palliative care for cancer and their families want to be told? A Canadian and Australian qualitative study. BMJ 2004;328:1343.

22 Lutfey K, Maynard DW. Bad news in oncology: how physician and patient talk about death and dying without using those words. Soc Psychol Q 1998;61:321-41.

23 Stivers T, Timmermans S. Always look on the bright side of life: making bad news bivalent. Res Lang Soc Interact 2017;50:404-18.

24 Timmermans S, Stivers T. Clinical forecasting: towards a sociology of prognosis. Soc Sci Med 2018;218:13-20.

25 Broom A, Kirby E, Kenny K, et al. Moral ambivalence and informal care for the dying. The Sociological Review 2016;64:987-1004.

26 Rodenbach RA, Norton SA, Wittink MN, et al. When chemotherapy fails: emotionally charged experiences faced by family caregivers of patients with advanced cancer. Patient Educ Couns 2019;102:909-15.

27 Dionne-Odom JN, Demark-Wahnefried W, Taylor RA, et al. The selfcare practices of family caregivers of persons with poor prognosis cancer: differences by varying levels of caregiver well-being and preparedness. Support Care Cancer 2017;25:2437-44.

28 Broom A, Kenny K, Kirby E, et al. The collective/affective practice of cancer survivorship. Br J Sociol 2019;70:1582-601.

29 Kirby ER, Kenny KE, Broom AF, et al. Responses to a cancer diagnosis: a qualitative patient-centred interview study. Supportive Care in Cancer 2020;28:229-38.

30 Pope C, Ziebland S, Mays N, et al. Analysing qualitative data. In: Pope C, Mays N, eds. Qualitative Research in Health Care. 3rd edn. Oxford, UK: Blackwell Publishing, 2006: 63-81.

31 Fitzpatrick R, Boulton M. Qualitative research in health care: I. The scope and validity of methods. J Eval Clin Pract 1996;2:123-30.

32 O'Brien BC, Harris IB, Beckman TJ, et al. Standards for reporting qualitative research: a synthesis of recommendations. Acad Med 2014;89:1245-51.

33 Smith AK, White DB, Arnold RM. Uncertainty-the other side of prognosis. N Engl J Med 2013;368:2448-50. 
34 Hancock K, Clayton JM, Parker SM, et al. Truth-telling in discussing prognosis in advanced life-limiting illnesses: a systematic review. Palliat Med 2007;21:507-17.

35 Langer SL, Brown JD, Syrjala KL. Intrapersonal and interpersonal consequences of protective buffering among cancer patients and caregivers. Cancer 2009;115:4311-25.

36 Morris SM, Thomas C. The carer's place in the cancer situation: where does the carer stand in the medical setting? Eur J Cancer Care 2001;10:87-95.

37 O'Callaghan MN, Baird C, Hiscock A, et al. Cancer caregivers advocate a patient-and family-centered approach to advance care planning. J Pain Symptom Manage 2014;47:1064-77.

38 Christakis NA. The ellipsis of prognosis in modern medical thought. Soc Sci Med 1997;44:301-15.
39 Jutel A. Truth and lies: disclosure and the power of diagnosis. Soc Sci Med 2016;165:92-8.

40 Ehrenreich B. Bright-sided: How the relentless promotion of positive thinking has undermined America. New York: Metropolitan Books, 2009.

41 Youll J, Meekosha H. Always look on the bright side of life: cancer and positive thinking. J Sociol 2013;49:22-40.

42 Collins A, McLachlan S-A, Philip J. How should we talk about palliative care, death and dying? A qualitative study exploring perspectives from caregivers of people with advanced cancer. Palliat Med 2018;32:861-9.

43 Olson RE, Connor J. When they don't die: Prognosis ambiguity, role conflict and emotion work in cancer caregiving. $J$ Sociol 2015;51:857-71. 